\title{
The Risk of Delayed Diagnosis in COVID-19 Era: Celiac Crisis
}

\author{
Alessia Angi ${ }^{1}$, Marina Cerruto ${ }^{1}$, Chiara Cauzzo ${ }^{1}$, Lucio Ceglie $^{1}$, Francesco Chiarelli ${ }^{1,2 *}$ and Annal- \\ isa Blasetti ${ }^{1}$
}

${ }^{1}$ Department of Pediatrics, “G. D’Annunzio” University of Chieti, Italy

${ }^{2}$ Department of Pediatrics, Center of Excellence on Aging “G. D’Annunzio” University of Chieti, Italy

Corresponding author: Francesco Chiarelli, Department of Pediatrics, Center of Excellence on Aging “G. D’Annunzio”

University of Chieti, Via dei Vestini n 5 Chieti, 66100 Italy

\begin{abstract}
ARTICLE INFO
Received: 幽 October 17, 2020

Published: 蔧 October 27, 2020

ABSTRACT

COVID-19 lockdown showed a decrease in pediatric emergency department visits mainly due to the fear of contracting SARS CoV-2 and it was potentially life-threatening for children. We describe a case of celiac disease in which the delayed access to health care led to a severe form of celiac crisis
\end{abstract}

Citation: Alessia A, Marina C, Chiara C, Lucio C, Francesco C, Annalisa B. The Risk of Delayed Diagnosis in COVID-19 Era: Celiac Crisis. Biomed J Sci \& Tech Res 31(3)-2020. BJSTR. MS.ID.005102.
Keywords: Lockdown; Pandemic; Celiac Disease; Diarrhoea; Hypoalbuminemia

Abbreviations: CD: Celiac Disease; GFD: Gluten Free Diet

\section{Introduction}

COVID-19 lockdown in Italy had a negative impact on common clinical practice showing a substantial decrease in pediatric emergency department visits. Undoubtedly, the closure of schools and sport activities led to a reduction of acute infections and traumas among children. However, there was also a delayed access to health care for severe illness (eg. diabetic ketoacidosis, peritonitis, sepsis, malignancies). This reflects mainly the reticence of parents and caregivers to risk exposure to SARS-CoV-2 and it is potentially life-threatening for children. We describe a case of celiac disease in which the delayed diagnosis resulting from the fear of contracting COVID-19 led to a severe form of celiac crisis, an entity almost disappeared in industrialized countries. The purpose of this manuscript is to highlight the effects of the recent pandemic on children's health and the need to educate parents and caregivers about the risks of delayed access to hospital care.

\section{Case Report}

A 15 month-old boy was admitted to our Pediatric Emergency Department for widespread edema, abdominal distention and weight loss. 15 days before admission he began having watery diarrhoea, episodic vomiting and worsening fatigue with walking refusal. There was no associated fever. His parents were also worried about his marked irritability and decreased oral intake, but they delayed access to hospital care due to their fear of contracting COVID-19. The past medical history was unremarkable except for constipation with episodic diarrhoea. The child had been fed with formula and by the age of 6 months with cereals, meat and vegetables. A deflection in growth curves was evident with the onset of weaning (from $75^{\text {th }}-90^{\text {th }}$ to $25^{\text {th }}-50^{\text {th }}$ percentile in weight; from $50^{\text {th }}$ to $25^{\text {th }}$ percentile in height). Family history was positive for celiac disease (paternal aunt). On admission the patient was afebrile with a heart rate of $110 \mathrm{bpm}$, a room air pulse oximetry of $100 \%$ and his blood pressure was $90 / 60 \mathrm{mmHg}$. His weight and height were $9,5 \mathrm{~kg}\left(10^{\text {th }}-25^{\text {th }}\right.$ percentile $)$ and $76 \mathrm{~cm}\left(7^{\text {th }}\right.$ percentile $)$ respectively. On physical examination he showed a significant periorbital and leg edema (Figure 1) as well as distended abdomen (Figure 2). Muscle atrophy with reduced motility of upper and lower limbs was also noted. He was estimated to be moderately dehydrated and received intravenous normal saline solution. Blood analysis revealed low levels of serum albumin $(2,4 \mathrm{~g} / \mathrm{L})$ and total proteins $(4,2 \mathrm{~g} / \mathrm{dL})$ with normality of electrolytes, renal and liver function tests. 


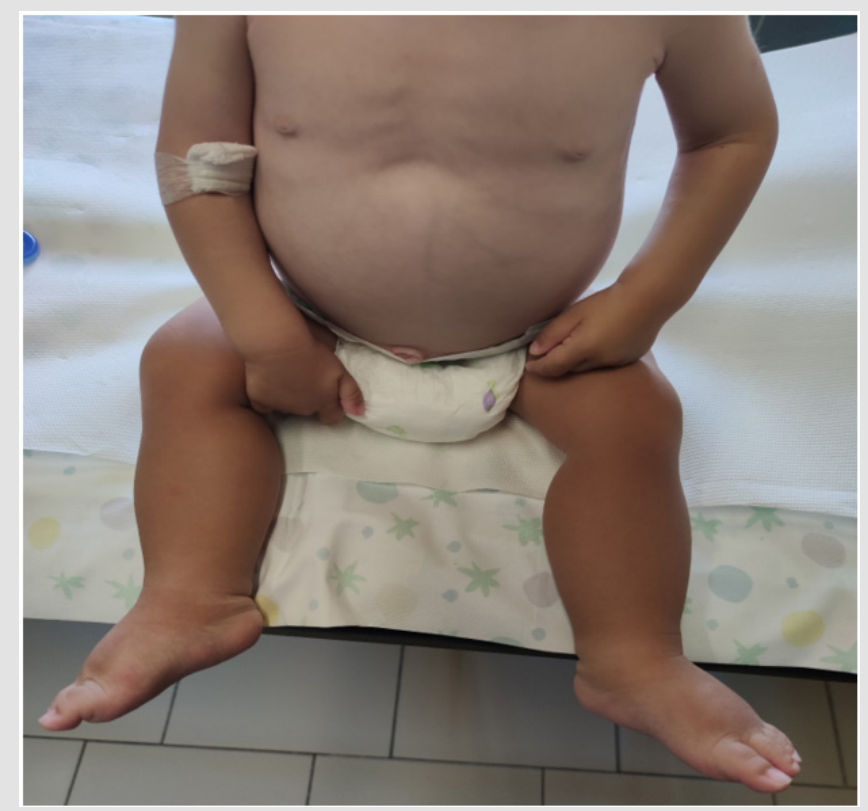

Figure 1: On admission edema was evident mainly on the child's face and lower limbs.

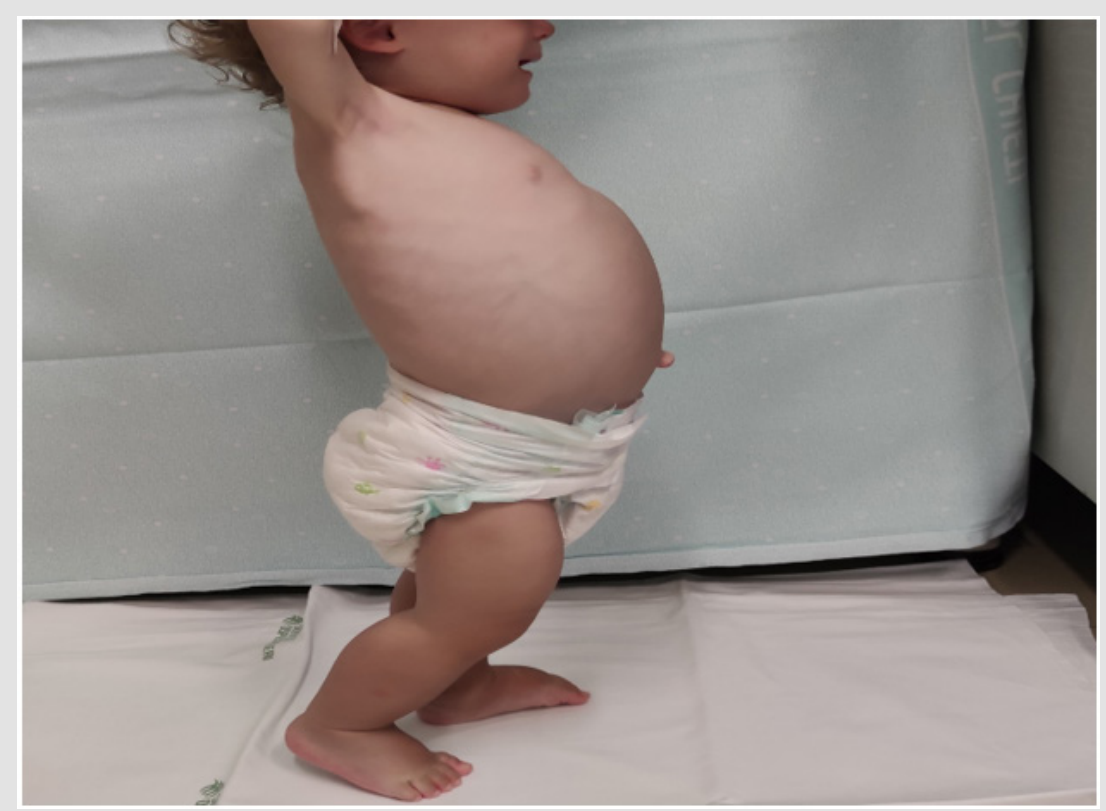

Figure 2: The child showed marked abdominal distention, widespread edema and scant adipose tissue.

There were no signs of metabolic acidosis on venous blood gas or proteinuria on urinalysis. His abdominal radiograph documented distended air-filled loops of small and large intestine without evidence of obstruction. Moreover, abdominal ultrasound showed free fluid within the bowel loops. A mild trasudative pericardial effusion was found on echocardiogram while lung ultrasound excluded pleural effusion. The electrocardiogram documented sinus rhythm. The common causes of infectious diarrhoea were excluded by stool cultures. Since the clinical history suggested celiac disease (CD), serum autoantibodies were checked and the diagnosis was confirmed following the latest ESPGHAN diagnostic guidelines [1]. In particular, the child showed high level positivity (>10 upper normal limit) of IgA anti-transglutaminase with anti-endomysial antibodies positivity in a second blood sample. Therefore, the patient was treated with a gluten free diet (GFD) and extensively hydrolysed protein formula. Despite a clinical improvement, albumin and serum sodium levels decreased $(2,2 \mathrm{~g} / \mathrm{L}$ and $134 \mathrm{mEq} / \mathrm{L}$ respectively) and his weight remained static. For this reason, methylprednisolone $(2 \mathrm{mg} / \mathrm{kg} /$ day $)$ was started on hospital day 8. After four days, the child became more active and started to show weight gain. Albumin and serum sodium levels reached normal values. Pericardial effusion slightly improved. The 
patient was discharged on a tapering dose of prednisone and a GDF giving recommendations for a strict clinical and instrumental follow-up. The parents provided the consent to collect and publish data and images of their son, in conformity with the Declaration of Helsinki.

\section{Discussion}

CD is a chronic small intestine immune-mediated enteropathy initiated by exposure to dietary gluten in genetically predisposed individuals [2]. The prevalence in the general population is $1 \%$ [3]. The main target organ is the small bowel, where the gluten inflammatory cascade causes a progressive mucosal damage leading to severe villous atrophy [4,5]. Clinically CD display a broad spectrum of intestinal (eg diarrhoea, constipation, vomiting, abdominal pain, weight loss) and extraintestinal symptoms (eg anaemia, dermatitis herpetiformis, neurologic disorders, hypertransaminasemia) [5,6]. The diagnosis is based on the findings of serum CD autoantibodies, particularly IgA anti-transglutaminase and anti-endomysial antibodies and villous atrophy at the intestinal biopsy [1]. Currently, the only treatment for CD is a lifelong, strict GFD [5]. In the majority of cases the natural history of CD is characterized by chronic evolution with and indolent course but a delayed diagnosis may be responsible for an acute fulminant form called celiac crisis, as observed in our patient. Celiac crisis is a potentially life-threatening condition characterized by severe gastrointestinal manifestations, hypoprotidemia, metabolic and electrolyte derangements requiring hospitalization [7].

Further to severe dehydration, the patient may present with neuromuscular weakness, cardiac arrhythmias, metabolic acidosis, seizures, ataxia, coagulopathy and acute kidney injury [6]. It may arise in patients with poor compliance to GFD or it may be the onset of $C D$ [8]. It is often precipitated by stress factors like surgery or infection [9] but in our case no such precipitant could be found. In our patient the delay in medical referral, due to the fear of contracting COVID-19, was clearly responsible for the severity of clinical presentation. The milestones of treatment are parenteral fluid replacement and GFD with gradual increase of caloric intake to avoid the risk of refeeding syndrome $[6,10]$. Sometimes celiac crisis may not respond to a GFD alone [11] requiring steroid treatment [9]. The use of systemic steroids for severe CD is not new and currently indications are treatment of refractory symptoms and celiac crisis [12]. Corticosteroids inhibit inflammation and cell death promptly reversing mucosal damage and metabolic derangements [12]. Jamma et al. [9] reported retrospectively that adult patients who received corticosteroids experienced rapid clinical improvement within 2 weeks of treatment initiation and were able to be maintained on GFD alone [9]. Mones et al. [11] described two pediatric cases of celiac crisis successfully treated with corticosteroids [11].
Interestingly our patient showed the same outcome with shortterm use of steroids. The aim of this manuscript is to highlight how the reduced access to hospital care during COVID-19 lockdown increase the risk of severe illness in children. In Italy, hospital statistics showed substantial decrease in pediatric emergency department visits reflecting primarily the reticence of parents and caregivers to risk exposure to SARS-CoV2 in a health-care setting [13]. Lazzerini et al. [13] describe 12 cases of delayed access to hospital care during the week 23-27 March 2020 across five hospitals. Half of the children were admitted to an intensive care unit and four died [13]. Despite the end of lockdown, this case report demonstrates that there is still a delayed access to health care so it is important to make parents aware that the risks of a delayed diagnosis can be much higher than those posed by COVID-19.

\section{Source of Fundings}

None.

\section{Confict of Interest/Disclosure Policy}

The authors have indicated they have no conflicts of interest relevant to this article to disclose.

\section{References}

1. Husby S, Koletzko S, Korponay Szabó I, Kurppa K, Mearin ML, et al. (2020) European Society Paediatric Gastroenterology, Hepatology and Nutrition Guidelines for Diagnosing Coeliac Disease 2020. J Pediatr Gastroenterol Nutr 70(1): 141-156.

2. Leonard MM, Sapone A, Catassi C, Fasano A (2017) Celiac disease and nonceliac gluten sensitivity: A review. JAMA 318(7): 647-656.

3. Husby S, Koletzko S, Korponay Szabó IR, Mearin ML, Phillips A, et al. (2012) European society for pediatric gastroenterology, hepatology, and nutrition guidelines for the diagnosis of coeliac disease. J Pediatr Gastroenterol Nutr 54(1): 136-160.

4. Valitutti F, Fasano A (2019) Breaking Down Barriers: How Understanding Celiac Disease Pathogenesis Informed the Development of Novel Treatments. Dig Dis Sci 64(7): 1748-1758.

5. Caio G, Volta U, Sapone A, Leffler DA, De Giorgio R, et al. (2019) Celiac disease: A comprehensive current review. BioMed Centr Medicine 17(1): 142 .

6. Guarino M, Gambuti E, Alfano F, Strada A, Ciccocioppo R, et al. (2020) Life-threatening onset of coeliac disease: A case report and literature review. BMJ Open Gastroenterol 7(1): e000406.

7. De Almeida Menezes M, Ribeiro Cabral VL, Lorena SS (2017) Celiac crisis in adults: A case report and review of the literature focusing in the prevention of refeeding syndrome. Rev Esp Enf Dig 109(1): 67-68.

8. Poudyal R, Lohani S, Kimmel WB (2019) A case of celiac disease presenting with celiac crisis: rare and life threatening presentation. J Community Hosp Intern Med Perspect 9(1): 22-24.

9. Jamma S, Rubio Tapia A, Kelly CP, Murray J, Najarian R, et al. (2010) Celiac Crisis Is a Rare but Serious Complication of Celiac Disease in Adults. Clin Gastroenterol Hepatol 8(7): 587-590.

10. Catassi C (2012) Celiac crisis/refeeding syndrome combination: New mechanism for an old complication. J Pediatr Gastroenterol Nutr 54(4): 442-443. 
11. Mones RL, Atienza KV, Youssef NN, Verga B, Rosh JR (2007) Celiac crisis in the modern era. J Pediatr Gastroenterol Nutr 45(4): 480-483.

12. Latorre M, Green PHR (2012) The role of corticosteroids in celiac disease. Dig Dis Sci 57(12): 3039-3041.

\section{ISSN: 2574-1241}

DOI: 10.26717/BJSTR.2020.31.005102

Francesco Chiarelli. Biomed J Sci \& Tech Res

(c) (P) This work is licensed under Creative

Submission Link: https://biomedres.us/submit-manuscript.php
13. Lazzerini M, Barbi E, Apicella A, Marchetti F, Cardinale F, et al. (2020) Delayed access or provision of care in Italy resulting from fear of COVID-19. Lancet Child Adolesc Health 4(5): e10-e11.

$\begin{array}{ll}\text { BIOMEDICAL } & \text { Assets of Publishing with us } \\ \text { RESEARCHES } & \text { - Global archiving of articles } \\ \text { - Immediate, unrestricted online access }\end{array}$

